\title{
Managers' Perceptions of Organizational Safety: Implication for the Development of Safety Culture
}

\author{
Marina Järvis ${ }^{1}$, Anu Virovere ${ }^{2}$, Piia Tint ${ }^{3},{ }^{1-3}$ Tallinn University of Technology
}

\begin{abstract}
A key feature of a company's safety culture is shared perceptions between managers and employees concerning the importance of safety. The purpose of the study was to assess senior managers' perceptions of the current safety culture in Estonian SMEs from different branches of industry, based on a sample of 463 senior managers. The relationships of different aspects of safety culture and safety management systems, senior managers' and employees' perceptions and attitudes to safety were explored through the deployment of different research measures and methods. In addition, a qualitative approach to assessing safety culture is presented. Studies of eight SMEs included observation, analysis of documentation and semistructured interviews with senior managers and focus group interviews with employees. This paper reports on the empirical examination of the relationship between a safety climate and a safety culture through a knowledge management dimension with a special focus on management of safety knowledge. The results of this study indicate that safety climate has impact on the three dimensions of safety culture, namely, psychological, behavioral and organizational aspects of safety culture. Several specific features of safety and knowledge management, such as management commitment to safety, safety information dissemination, communication and workers' involvement in safety were found to influence the relationship between a safety climate and a safety culture. It is concluded that the development of 'communities of practice' is an effective way for employees to exchange explicit and tacit safety knowledge.
\end{abstract}

Keywords: Knowledge management, organizational values, safety climate, safety culture, safety knowledge.

\section{INTRODUCTION}

Studies have revealed that following occupational safety initiatives leads to an average increase of $71 \%$ in cost benefits, $66 \%$ in productivity and $44 \%$ in quality [1]. It is estimated that $4 \%$ of annual global GDP, or USD 1.25 trillion, is lost due to the direct and indirect costs of occupational accidents and diseases (such as lost working time, interruption of production, medical expenses, and workers' compensation) [2]. Organizations in the United States lose up to 170 billion dollars annually due to occupational injuries (as cited in [3]). The UK Health and Safety Executive estimates the costs to individual occupational accidents and work-related ill health to be between GBP 10.1 and GBP 14.7 billion (or EUR 11.5 to 16.7 billion); the costs to employers to be between GBP 3.9 and GBP 7.8 billion (approximately EUR 4.4 to EUR 8.9 billion) and the costs to the society of workplace accidents and work-related ill health to be between GBP 20 to GBP 31.8 billion (approximately EUR 22.7 to EUR 36.1 billion) [4]; [5]. At the same time, a good safety management system (SMS) can positively affect not only accident rates and safety performance of organization, but also have a positive influence on competitiveness performance, economic and financial performance of an organization and on the control of workers' safe behavior [5]; [6]. According to [2], many companies, especially small and medium-sized enterprises (SMEs), have viewed occupational health and safety $(\mathrm{OH} \& \mathrm{~S})$ as a necessary element of compliance rather than as a contributory factor to the economic viability of their organization. At the same time, estimates suggest that these enterprises have serious problems aggravated by limited access to human, economic, technological resources as well as lack of relevant safety knowledge in order to deal with OH\&S [7].

A safe and healthy working environment is an important element of work life quality [8]. Safety through technical design is still entirely relevant to ensuring safe and healthy work systems, but in itself it is now regarded as insufficient. As part of safety management system, it is important to focus on managerial and organizational factors. Attention in recent years has shifted towards attempting to better understand the psychological and social preconditions for employees' unsafe behavior and accident causation. Over the past two decades, many researchers [6]; [9-12] and practitioners have shown increasing interest in the concept of safety culture because of its impact on safety outcomes of the organization such as injuries, fatalities, and other incidents.

When safety becomes a value and is demonstrated through employers' and employees' individual attitudes, perception, and behavior, the process develops into a safety culture. The concept of 'safety culture' has been developed and is seen as a sub-unit of organizational culture, alluding in particular to individual characteristics, the nature of the work tasks and the organizational features that may affect and influence organization's on-going health and safety performance [10]. Schein [13] claims that the way in which senior managers reward, instruct, allocate resources and their attention as well as behavior under the pressure, will be particularly salient in shaping organizational (safety) culture. Other researchers [14]; [15] suggested that perceptions of senior managers' attitudes and behaviors in relation to the health and safety, well-being of workforce will form the basis for the safety behavior of employees, and therefore, the safety performance of the organization.

Previous collaborative research by the authors has shown empirically that many managers have started showing interest in safety performance and their conclusion is that intervention should be directed towards employees and employees' behavior [16]. However, the newest investigations show that the changing of safety climate and culture in organizations (in 
particular, in SMEs) is also really a matter of changing managers' behavior. The behavior-based safety approach may be effective for reactive safety management by modifying behavior and improving compliance behavior. Such behavior is also one of the main issues (together with situations and person factors) identified in the model of safety culture as the key factor which is applicable to the accident causation chain at all levels of an organization [10]; 17]. Positive safety culture requires stronger institutional pressure, where all the employees and the employer commit and participate in health and safety activities as well as relevant organizational structure in order to share values and practical safety knowledge and to exchange (tacit and explicit) knowledge [6]; [18]; [19].

The most common construct in the safety culture survey is the perception of leadership and management/supervisors' attitudes and behaviors around safety [20]; [21]. According to [3]; [18], management should encourage safe behavior of employees. Like previous research [7], this suggests leadership (management and supervisors) should spend more time on the floor with employees and build trust, which is vital for the opportunity to convert tacit knowledge into explicit shared knowledge. Management commitment can also be demonstrated by allocation of the resources in the field of OH\&S.

There are many quantitative and qualitative data collection tools available that can be used to measure the psychological, behavioral and situational/organizational aspects of safety culture [3]; [10]; [11]; [18]; [22]. Cooper emphasizes the necessity to use more than one methodological angle (the socalled triangulation) in order to evaluate overall safety culture in an organization [10]. Recent reviews of safety culture measures have revealed many potential factors that could make up an overall safety culture [11]; [20]. However, there is still little consensus available regarding the reliable core factors of safety culture and whether the measure of safety climate can be a reliable indicator of overall safety culture. Frazier with colleagues have addressed the necessary core safety culture factors, for example, peer support for safety, safety management systems, personal responsibility for safety, and management support for safety [3].

The current study was conducted in Estonia for various reasons. First, the recent annual reports of the National Labour Inspectorate (2008-2011) present evidence that working environment and the employer awareness concerning OH\&S in Estonian manufacturing SMEs need improvement. Second, although significant progress has been made in accident prevention in Estonia in recent years, empirical evidence of the combined fatal and serious incident rates, especially among young and new workers, suggests that this is still an area where greater public policy intervention might be warranted. Third, the results from the analysis of the cost of implementing the main topics of Occupational Health and Safety regulations for Estonian enterprises [23] revealed that employers considered OH\&S a cost burden, especially costly for the SMEs. This study concludes that Estonian employers waste much time and money due to the lack of relevant information and knowledge in the field of OH\&S and there is a need for radical change [23]. In sum, the public policy goal of promoting a high level of SMS and safety culture, particularly in the predominant SMEs sector has received very little attention in Estonia.

This article examines relationships between a safety climate and a safety culture, tests an innovative conceptual safety culture model proposed in previous research [24], based on employers' responses. Focus is given on organizational safety culture and the structure or architecture of employees' and employers' attitudes to safety as part of that culture, as well as the ability to learn, which also should mean changes in employees' behavior in order to enhance safety culture.

The authors emphasize that the potency of the reciprocal model [24]; [25] for analyzing safety culture may be different in any given situation and might be influenced by potentially important internal and external organizational factors like environment, context, governance, relevant regulations, design etc. The reciprocal interactions among psychological, behavioral and organizational variables, which have been recognized and reflected in the major safety culture models, as well as the added knowledge variable indicate that the four dimensions to measure the overall safety culture of an organization are psychological, behavioral, organizational and knowledge aspects of safety culture. Therefore, in order to validate the assessment of safety climate as an effective means of measuring the overall safety culture, three hypotheses are postulated here:

H1: Safety climate has an impact on the psychological aspect of safety culture and contributes to managing safety knowledge.

$\mathrm{H} 2$ : Safety climate has an impact on the behavioral aspects of safety culture and contributes to managing safety knowledge.

H3: Safety climate has an impact on the organizational aspects of safety culture and contributes to managing safety knowledge.

\section{METHODOLOGY}

\section{Research Design and Instrumentation}

Since OH\&S is a multidisciplinary and complex field, some researchers [14]; [10] have argued that safety culture cannot be completely understood through traditional quantitative methods, which attempt to break down a phenomenon in order to study its individual components. Safety culture therefore requires the use of both qualitative methods [26] and quantitative methods. Cooper [10] argues that determination of safety culture through a safety climate measure (questionnaire) has a tendency to focus purely on the way people feel and how they perceive safety in an organization rather than the real and essential aspects of safety culture, like the actual behavior of employees, the real safety situation and safety environment in an organization. The authors of the paper in their previous research [7]; [16]; [27] have investigated the differences between 'formal' safety and 'real' safety in Estonian SMEs in different industries, indicating some important safety flaws and drawing attention to 
contextual variables in the development and management of safety cultures.

This research employed quantitative methods in order to explore psychological, behavioral and organizational/ environmental aspects of safety culture (employers' and employees' attitudes, perceptions toward OH\&S, values, conflicts and relationships, information dissemination, risk awareness and employees' involvement). In addition, qualitative methods were used in order to focus on a limited number of case studies and individuals, producing in-depth information, to investigate real safety situation in SMEs, with the intention to bring understanding to the concept of safety culture and real safety behavior in the investigated companies (Fig. 1).

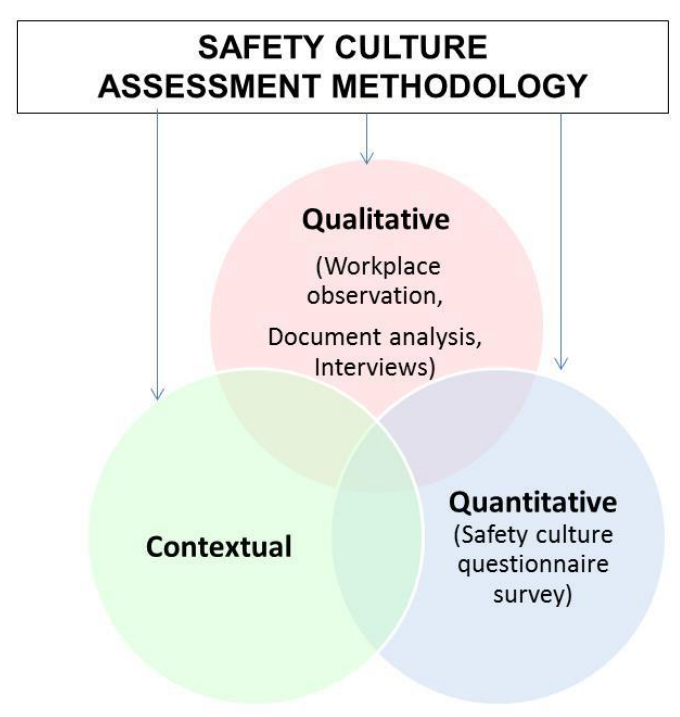

Fig. 1. Methodology of safety culture assessment.

According to Cooper [10], alternative or supportive measures for capturing and analyzing the psychological aspects of safety culture include focus group interviews and discussion groups and document analysis. The behavioral aspects of safety culture can be evaluated via observations, and from such sources as risk assessment, accidents and nearmiss analysis and reporting documentation, standard operating procedures, the number of weekly inspections completed, the number of audits conducted. The situation aspects of safety culture can be examined from organizational policies, operating procedures, management systems, audits and communication flows [28] as well as from risk assessment reflecting working environment (occupational hazards) and via safety audits of SMS. Thus, a qualitative study approach allows studying the complexity of factors - as they are related to workers, their behavior and interactions with the SMS of an organization.

\section{Safety Interviews. Case Studies}

Measurement of safety culture in terms of the attitudes and perceptions of respondents (employees) about the priorities of safety in their organization is essential, but a survey (questionnaire) alone cannot measure the actual behavior in the workplace and the real safety situation in an organization. Thus, the qualitative studies were conducted by the authors in order to understand the underlying dynamic processes that need to be supported in pursuit of a 'good' safety culture and to determine organization's true motives for developing SMS, norms and rules for dealing with an occupational risk.

Applying the model of Cooper [10] into measurements, the supportive research methods were also adopted. The case studies were intended to promote a better understanding of the rationale of current safety culture in Estonian manufacturing SMEs. Results from qualitative studies [7]; [16]; [25]; [27] were used in order to complement and verify the results gained from the safety survey. The exploratory study was based on workplace visits, observations, audits and semistructured interviews with senior managers, as well as focus group interviews with workers. Observations of safety culture performance indicators in the workplace were performed based on the checklist. The visual assessment includes, for example, hazard registers; workplace layout and cleanliness; personal protective equipment usage and storage; working conditions; condition of plant/ equipment; safety information displayed in general and at workstations etc. The selected enterprises were SMEs (less than 250 workers), from different branches of industry (the metal industry (3), textile industry (2), manufacture of devices and plastic processing industry (2), and printing industry (1)) and from various geographical locations in Estonia. Eight semi-structured face-to-face interviews with senior managers in charge of production operations, quality sections of their companies were conducted. The study focused specifically on the perceptions of senior managers, exploring their attitudes and management concern regarding safety, how they care for employees and their enforcing of safety policies and regulations within their respective business and industry; knowledge in $\mathrm{OH} \& \mathrm{~S}$, their commitment to safety, responsibility, cooperation with $\mathrm{OH} \& \mathrm{~S}$ specialists (occupational health physicians) [27]. The interviews were conducted in the Estonian and Russian languages. Each interview with managers lasted two hours on average and was recorded. Interviews were then fully transcribed and analyzed. Data for this exploratory study were gathered from 8 focus group interviews with 22 industrial workers (13 males and 9 females) [27]. A simple random sample was selected from workers employed at the SMEs. The objective was to gather information about workers' attitudes and perceptions to safety, shared visions and values, safety practices, safety communication and feedback, participation in safety committees, peer support for safety among co-workers, safety knowledge, and their involvement in safety management activities. Each focus group session lasted 45 minutes on average and was recorded. Interviews were then fully transcribed and analyzed. Every effort was made to protect the privacy, confidentiality, and anonymity of individuals and organizations participating in this study. The interviews were analyzed in the previous study [7]; [27]. In addition, the SMS were evaluated in each investigated SMEs through the audit and document analysis for key safety culture 
indicators. Relevant supplementary safety documents, such as safety strategy and policy, plan and instructions, risk assessment, safety rules and procedures, safety audits and inspections, safety meetings/ committees, safety records, including incident and accident investigations, training and meeting records, were also carefully analyzed in order to compliment and verify the data collected during the interviews. Detailed results from the working environment and conditions in the investigated SMEs were analyzed and presented in previous research [7]; [16]; [27].

\section{Safety Survey}

The statistical survey results were complemented by the data acquired from a national Work Environment questionnaire survey conducted by Statistics Estonia in 2009, which is a representative survey using employer-employeelinked data, designed specifically for studying working environment and measuring safety attitudes, perceptions, values, conflicts and relationships, information dissemination, communication with respect to safety, safety knowledge transfer, job interest and satisfaction, perceived responsibility for and involvements in safety issues, commitment, risk awareness, working conditions, and safety measures. The respondents were requested to provide their perceptions of these statements. The questionnaire also included additional items not relevant to the present research and article. Five ordered response levels were used in the survey. Respondents were required to rank the factors on a 5-point Likert-type scale between $1=$ strongly disagree and $5=$ strongly agree to each of the statements found in the questionnaire. The substantive parts of the paper present recent comparative survey evidence from the quantitative and qualitative safety survey.

\section{Data Sample Characteristics}

The majority of empirical studies limit their sample to one organization from a specific sector which can cause some doubt about their external validity [29]. Thus, to achieve as high degree of generalization as possible for the results of the current work, the authors considered the target population made up of manufacturing SMEs from different branches of industry (see Table 1).

There were two similar questionnaires for employers and employees to measure the effects of safety climate upon the overall safety culture and management of safety knowledge. Two questionnaires were administered anonymously to employees and employers from SMEs from different branches of industry. The current survey comprises a sample of 463 employers and 1757 employees who filled out the questionnaires and participated in the study. The employees' questionnaire was analyzed in our previous study [24].

A special feature of the survey is that it is the first linked data set of both employees and employers in SMEs exploring inter alia issues of employees' involvement, representation, responsibility for workplace safety and health, management and employees' commitment to safety; support; importance and relevance of the safety requirements and procedures, training, information and safety knowledge; how resources are allocated; how safety is valued and appreciated throughout the investigated organizations. The higher response rate was from the organizations with less than 50 employees (Table 1). We found companies with less than 250 employees to be more reluctant to respond to the questionnaire, which led to a lower response rate from that type of companies.

TABLE I

DistRIBUTION OF SAMPLE By ACTIVITY, SizE

\begin{tabular}{|l|l|l|}
\hline ACTIVITY SECTORS, Industry & POPULATION & $\begin{array}{l}\text { RESPONSE } \\
\text { RATE, \% }\end{array}$ \\
\hline Agriculture, forestry, fishing & 39 & 80.1 \\
\hline Mining industry & 47 & 70.9 \\
\hline $\begin{array}{l}\text { Processing industry, textile-, } \\
\text { chemical-, paper-, plastics-, wood-, } \\
\text { metal industry }\end{array}$ & 49 & 58.9 \\
\hline Electricity-, gas supplier & 40 & 71 \\
\hline $\begin{array}{l}\text { Water supply; sewerage; waste- and } \\
\text { pollution treatment }\end{array}$ & 43 & 66.8 \\
\hline Construction & 51 & 55.8 \\
\hline $\begin{array}{l}\text { Wholesale business, retail business. } \\
\text { Machinery, vehicle repair }\end{array}$ & 56 & 57.1 \\
\hline Transport, warehousing & 32 & 56.6 \\
\hline Other manufacturers & 27 & 55.8 \\
\hline Health care, social assistance & 79 & 64.5 \\
\hline TOTAL COMPANIES & $\mathbf{4 6 3}$ & $\mathbf{6 3 . 8}$ \\
\hline SIZE (no. employees) & No OF & $\begin{array}{l}\text { RESPONSE } \\
\text { RATE, \% }\end{array}$ \\
\hline 5-9 & 150 & 27.6 \\
\hline $10-49$ & 197 & 34.9 \\
\hline $50-249$ & 110 & 19.5 \\
\hline More than 250 & 6 & 18 \\
\hline TOTAL COMPANIES & $\mathbf{4 6 3}$ & 100 \\
\hline & & \\
\hline
\end{tabular}

\section{RESULTS AND DISCUSSION}

\section{Senior Managers' Safety Culture Survey}

The data were analyzed using the Statistical Package for Social Science (SPSS 17.0) software. Statistical t-test of the mean was conducted to check the entire population's likely response to the issues raised in the questionnaire, based on the sample's ratings. The significance level of hypothesis testing was set as 0.05 , which means that there is only $5 \%$ probability that the relationship was due to a chance occurrence. The critical rating was set up as ' 3 ' because by the definitions of the rating scale, rating above ' 3 ' represented 'agree' or 'strongly agree' with the statements of the questionnaire. The number of factors that comprise safety culture varied from 3 to 19 [30].

The current survey and test results show that all ten (10) statements are statistically significant (Table 2) for the employers. This indicates that all the factors are important in determining the effects of safety climate on a safety culture. Factor analysis was applied to the thirty (30) factors stating the effects of positive climate in order to identify the possible underlying patterns among the original variables. 
TABLE II

ONE-SAMPLE $T$-TEST OF SIXTEEN SAFETY CLIMATE STATEMENTS

\begin{tabular}{|c|c|c|c|c|}
\hline \multirow[b]{2}{*}{ Item } & \multirow{2}{*}{ Statements } & \multicolumn{3}{|c|}{ Test Value $=\mathbf{3}$} \\
\hline & & $\begin{array}{l}\text { Mean } \\
\text { Differ } \\
\text { ence }\end{array}$ & $t$ & Sig. \\
\hline 1_Sc & $\begin{array}{l}\text { Positive safety climate enhances } \\
\text { information and safety knowledge } \\
\text { exchange }\end{array}$ & 1.268 & 36.450 & 0.000 \\
\hline 2_Sc & $\begin{array}{l}\text { Positive safety climate promotes } \\
\text { employees' involvement in health and } \\
\text { safety activities and improves safety } \\
\text { communication }\end{array}$ & 1.076 & 31.070 & 0.000 \\
\hline 3_Sc & $\begin{array}{l}\text { Positive safety climate enhances safety } \\
\text { knowledge dissemination and } \\
\text { establishing of Communities of } \\
\text { Practice }\end{array}$ & .951 & 38.453 & 0.000 \\
\hline 4_Sc & $\begin{array}{l}\text { Positive safety climate promotes the } \\
\text { management commitment to safety, } \\
\text { enhances the effectiveness of allocation } \\
\text { of resources }\end{array}$ & .998 & 41.235 & 0.000 \\
\hline 5_Sc & $\begin{array}{l}\text { Positive safety climate has a positive } \\
\text { impact on management commitment to } \\
\text { safety and law compliance (labor and } \\
\text { safety legislation) and thus increases } \\
\text { trust }\end{array}$ & .674 & 11.919 & 0.000 \\
\hline 6_Sc & $\begin{array}{l}\text { Positive safety climate improves } \\
\text { relationships between employer and } \\
\text { employees and decreases workplace } \\
\text { conflicts }\end{array}$ & .706 & 12.089 & 0.000 \\
\hline 7_Sc & $\begin{array}{l}\text { Positive safety climate promotes } \\
\text { managers' support, their willingness to } \\
\text { provide feedback }\end{array}$ & .585 & 9.843 & 0.000 \\
\hline 8_Sc & $\begin{array}{l}\text { Under the positive safety climate, } \\
\text { safety procedures, rules and standards } \\
\text { tend to be followed and fulfilled }\end{array}$ & .734 & 18.976 & 0.000 \\
\hline 9_Sc & $\begin{array}{l}\text { Positive safety climate enhances the } \\
\text { effectiveness of risk management and } \\
\text { improves the status of safety personnel }\end{array}$ & .678 & 15.861 & 0.000 \\
\hline 10_Sc & $\begin{array}{l}\text { Under the positive safety climate, } \\
\text { safety is valued by senior managers and } \\
\text { the possibilities are created for } \\
\text { employees to participate in the } \\
\text { decision-making process }\end{array}$ & .659 & 15.156 & 0.000 \\
\hline
\end{tabular}

This method is used to uncover the latent structure (dimensions) of a set of variables by measuring correlation of the different factors and thus weeds out the ones that are not related to each other. Factor analysis allows determining the number and nature of common factors that result in correlations among the factors and obtaining the understanding of the nature and dynamics of their relationships. The combination of the factors into a principal component helps to evaluate and explain the importance of combined factors. Principal components are extracted by varimax rotation of the original variable and each consecutive component is uncorrelated to the other. The Kaiser method was used to pick factors with eigenvalues greater than 1.0. This method reduces the huge amount of data and separates them into single uncorrelated component. Factor loadings above 0.6 are usually considered 'high' and those below 0.4 are 'low'. After the application of the factor analysis, ten (10) factors were grouped into principal components under each main category.

In this study we identified four (4) main categories using a scree plot. Scree plots and eigenvalues greater than one were used to determine the number of factors in each data set. The scree plot for the eigenvalues of 10 variables (factors) in descending order is provided in Fig. 2.

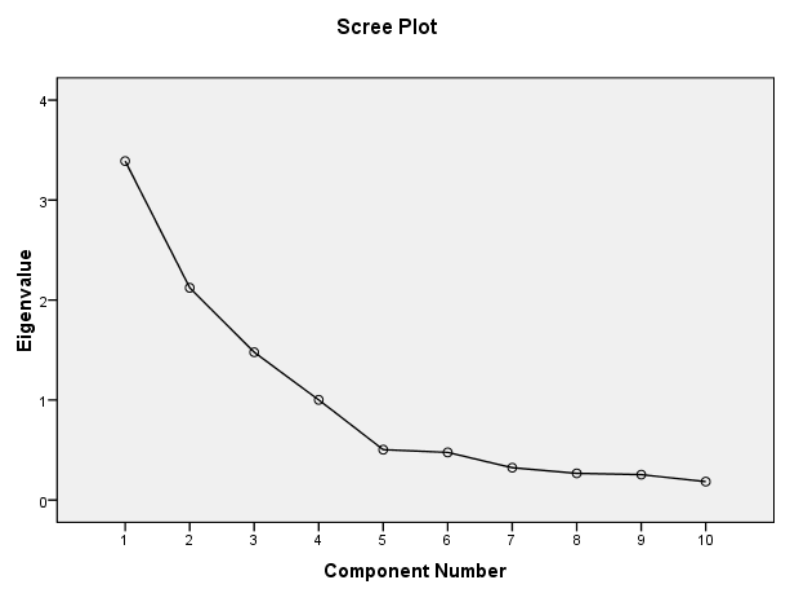

Fig. 2. Scree plot of the principal component analysis.

The last real factor is considered to be the point before which the first scree begins [31]. Factors with eigenvalues lower than one were not significantly indicated in the first scree plot. Four (4) principal components were extracted and the related factors are shown in Tables 3, 4 and 5, which were later on combined into three (3): 'organizational', 'psychological' and ' 'behavioral' aspects of safety culture.

Table 3 shows that the communalities are high (.673 to $.875)$, the number of expected factors is relatively small (4), and the model error is low due to the high communalities. Therefore, the population factor structure can be adequately recovered.

TABLE III

COMMUNALITIES

\begin{tabular}{|c|c|c|}
\hline Item & Initial & Extraction \\
\hline 1_Sc & 1.000 & .762 \\
2_Sc & 1.000 & .818 \\
3_Sc & 1.000 & .832 \\
4_Sc & 1.000 & .836 \\
5_Sc & 1.000 & .836 \\
6_Sc & 1.000 & .875 \\
7_Sc & 1.000 & .843 \\
8_Sc & 1.000 & .821 \\
9_Sc & 1.000 & .696 \\
10_Sc & 1.000 & .673 \\
\hline
\end{tabular}


TABLE IV

TOTAL VARIANCE EXPLAINED

\begin{tabular}{|c|c|c|c|c|c|c|}
\hline \multirow[b]{2}{*}{ Item } & \multicolumn{3}{|c|}{ Initial Eigenvalues } & \multicolumn{3}{|c|}{$\begin{array}{l}\text { Rotation Sums of Squared } \\
\text { Loadings }\end{array}$} \\
\hline & Total & $\begin{array}{l}\% \text { of } \\
\text { Variance }\end{array}$ & $\begin{array}{l}\text { Cumulativ } \\
\text { e } \%\end{array}$ & Total & $\begin{array}{l}\% \text { of } \\
\text { Variance }\end{array}$ & $\begin{array}{l}\text { Cumul. } \\
\%\end{array}$ \\
\hline 1_Sc & 3.390 & 33.902 & 33.902 & 2.555 & 25.545 & 25.545 \\
\hline 2_Sc & 2.123 & 21.230 & 55.132 & 2.277 & 22.775 & 48.320 \\
\hline 3_Sc & 1.478 & 14.781 & 69.912 & 1.698 & 16.981 & 65.301 \\
\hline 4_Sc & 1.002 & 10.017 & 79.929 & 1.463 & 14.629 & 79.929 \\
\hline 5_Sc & .503 & 5.035 & 84.964 & & & \\
\hline 6_Sc & .476 & 4.760 & 89.724 & & & \\
\hline 7_Sc & .323 & 3.232 & 92.956 & & & \\
\hline 8_Sc & .267 & 2.669 & 95.625 & & & \\
\hline 9_Sc & .254 & 2.537 & 98.162 & & & \\
\hline 10_Sc & .184 & 1.838 & 100.000 & & & \\
\hline
\end{tabular}

Extraction Method: Principal Component Analysis.

TABLE V

ROTATED COMPONENT MATRIX

\begin{tabular}{|c|c|c|c|c|}
\hline & \multicolumn{4}{|c|}{ Component } \\
\cline { 2 - 5 } & 1 & 2 & 3 & 4 \\
\hline 1_Sc & .045 & .844 & .214 & .055 \\
2_Sc & .129 & .875 & .071 & .178 \\
3_Sc & .107 & .087 & .901 & .028 \\
4_Sc & .053 & .128 & .902 & .062 \\
5_Sc & .903 & .072 & .119 & .031 \\
6_Sc & .927 & .121 & .023 & .030 \\
7_Sc & .912 & .092 & .057 & -.009 \\
8_Sc & .023 & .082 & .045 & .901 \\
9_Sc & .010 & .366 & .051 & .748 \\
10_Sc & .122 & .780 & .000 & .225 \\
\hline
\end{tabular}

Extraction Method: Principal Component Analysis.

Rotation method: Varimax with Kaiser Normalization.

Rotation converged in 5 iterations.

TABLE VI

ORGANIZATIONAL ASPECTS OF SAFETY CULTURE

\begin{tabular}{|c|l|c|}
\hline Item & \multicolumn{1}{|c|}{ Factors } & $\begin{array}{c}\text { Factor } \\
\text { loading }\end{array}$ \\
\hline 3_Sc & $\begin{array}{l}\text { Positive safety climate enhances safety knowledge } \\
\text { dissemination and establishing of Communities of } \\
\text { Practice. }\end{array}$ & 0.901 \\
4_Sc & $\begin{array}{l}\text { Positive safety climate promotes the management } \\
\text { commitment to safety, enhances the effectiveness of } \\
\text { allocation of resources. }\end{array}$ & 0.902 \\
8_Sc & $\begin{array}{l}\text { Under the positive safety climate, safety procedures, } \\
\text { rules and standards tend to be followed and fulfilled. }\end{array}$ & 0.901 \\
9_Sc & $\begin{array}{l}\text { Positive safety climate enhances the effectiveness of } \\
\text { risk management and improves the status of safety } \\
\text { personnel. }\end{array}$ & 0.748 \\
\hline
\end{tabular}

Safety Climate and Organizational Aspects of Safety Culture

The first principal component is extracted and the related factors are shown in Table 6. This principal component is related to the organizational/ situational aspects of safety culture based on the perception survey of senior managers. The statistical t-test results from senior managers' responses (see Table 2) also show that related factors (3_Sc, 4_Sc, 8_Sc and 9_Sc) are statistically significant and it means they have a positive effect on a safety climate based on senior managers' responses. Thus, hypothesis 1 was not rejected and safety climate was established to affect the organizational aspects of safety culture.

A positive safety climate promotes the commitment of management to safety, which has been recognized as a basic element of safety culture. Management support of safety has also led employees to accept responsibility and ownership for safety. These results are consistent with Zohar [32] studies. A review of the literature reveals the importance of managers' support to safety and leadership for safety culture and effective SMS.

According to the results from employees' and employers' perception survey, there are common organizational factors which have a positive impact on the organizational aspects of safety culture, for instance: promotion of management concern and commitment to safety, providing necessary resources as well as intention to follow safety procedures by employees.

\section{Safety Climate and Behavioral Aspects of Safety Culture}

The related factors of the second principal component are shown in Table 7 . These three factors shed light on the relationship between a safety climate and the behavioral aspects of safety culture. The statistical t-test results from senior managers' responses (see Table 2) also show that three related factors (1_Sc, 2_Sc, 10_Sc) are statistically significant and it means they have a positive effect on a safety climate based on senior managers' responses. Thus, hypothesis 2 was not rejected and safety climate was established to affect the behavioral aspects of safety culture.

TABLE VII

BeHAVIORAL ASPECTS OF SAFETy CUlture

\begin{tabular}{|c|l|c|}
\hline Item & \multicolumn{1}{|c|}{ Factors } & $\begin{array}{c}\text { Factor } \\
\text { loading }\end{array}$ \\
\hline 1_Sc & $\begin{array}{l}\text { Positive safety climate enhances information and } \\
\text { safety knowledge exchange. } \\
\text { Positive safety climate promotes employees' } \\
\text { involvement in health and safety activities and } \\
\text { improves safety communication. }\end{array}$ & 0.844 \\
10_Sc & $\begin{array}{l}\text { Under the positive safety climate, safety is valued by } \\
\text { senior managers and the possibilities are created for } \\
\text { employees to participate in the decision- making } \\
\text { process. }\end{array}$ & 0.780 \\
\hline
\end{tabular}

The current research, in line with some studies [6]; [33], suggests that managers have a direct influence through their positive attitudes towards safety and through their positive attitudes, active commitment and behavior.

According to the results from employees' [24] and employers' perception survey, there are common factors which have a positive impact on the behavioral aspects of safety culture, but employees emphasized that the positive safety climate enhances not only employees' personal responsibility, but also contributes to co-workers' peer support to safety. 
Safety Climate and Psychological Aspects of Safety Culture

The third principal component is extracted and the three related factors are shown in Table 8.

This principal component is related to the psychological aspects of safety culture based on the perception survey of senior managers. Table 8 indicates that three factors (5_Sc, 6_Sc, 7Sc) are all significantly important. Thus, hypothesis 3 was not rejected and safety climate was established to influence the psychological aspects of safety culture.

\section{TABLE VIII}

PSYCHOLOGICAL ASPECTS OF SAFETy CULTURE

\begin{tabular}{|c|l|c|}
\hline Item & \multicolumn{1}{|c|}{ Factors } & $\begin{array}{c}\text { Factor } \\
\text { loading }\end{array}$ \\
\hline 5_Sc & $\begin{array}{l}\text { Positive safety climate has a positive impact on } \\
\text { management commitment to safety and law } \\
\text { compliance (labor and safety legislation) and thus } \\
\text { 6_Sc }\end{array}$ & $\begin{array}{l}\text { increases trust. } \\
\text { Positive safety climate improves relationships between } \\
\text { an employer and employees and decreases workplace } \\
\text { conflicts. }\end{array}$ \\
7_Sc & $\begin{array}{l}\text { Positive safety climate promotes managers' support, } \\
\text { their willingness to provide feedback and to allocate } \\
\text { resources in order to activate safety management } \\
\text { system. }\end{array}$ & 0.903 \\
\hline
\end{tabular}

Managers have influence through their support, funding for establishing and development of the SMS. These findings are consistent with [6].

To compare the results from employees' and employers' perception survey, it is essential to underline that a positive safety climate contributes to the employees' job satisfaction, creativeness and innovation.

\section{The Organizational Context of Safety Culture}

As described in the proposed model, based on the above analysis, safety climate has a significant impact on all three aspects of overall safety culture, like organizational, behavioral and psychological aspects. However, perception surveys are not enough to assess and evaluate the existing overall safety culture and real safety behavior in an organization.

The statistical analysis of safety culture questionnaires shows many organizations with an outstanding safety culture and positive safety attitudes. However, qualitative data indicate some important safety weaknesses and aspects which should be included in the process of evaluation of safety culture in an organization [7]. The results from the case studies, workplace observation, document analysis and interviews with senior managers as well as focus group interviews with employees, collectively contributed to a comprehensive description and assessment of the safety culture in manufacturing SMEs. Detailed results from qualitative survey studies, working environment and conditions in the investigated SMEs were analyzed and presented in previous research [7]; [16]; [25]; [27]; [25]; [34].

There is a need for a holistic exploration of safety culture, which is influenced by both structure and processes in an organization [35]. There are three major interrelated elements/forces which are simultaneously influencing the behavior of the employees within organizations. These forces are the structure (which outlines the formal organization, i.e., the proposed allocation of power and responsibilities, mechanism of communication, coordination and control), culture (outlines assumption, individual and group values, attitudes, beliefs, risk perceptions, competencies, norms, principles, and patterns of behavior) and processes (rules, procedures, supervision). Together they provide the context of behavior, i.e., safety behavior, in an organization.

Qualitative approaches to safety culture assessment in the current study provided by workplace observation, document analysis and safety interviews indicated some important safety flaws [7]; [27]. The main aspects of safety culture are analyzed and presented below:

- Safety is a clearly recognized value in an organization. Most of the investigated SMEs showed rather a positive attitude towards contributing to safety: developing safety practices and written work procedures, risk assessment, investigating occupational accidents, providing safety training and occupational health services for the employees. However, the main shortfalls of the SMS were in gaps between formal and real safety that was discovered [7]. Qualitative results obtained show that in all investigated enterprises, safety is generalized as a formal or propagated value [7]; [36], safety was not valued throughout all investigated SMEs due to lack of everyone's commitment to safety. Still, the attitudes of the employees and employers were generally positive, many differences were found between work groups, and between management and staff. Employees were not willing to talk about safety issues and they did not actively participate in health and safety activities. Therefore strong safety communication problems exist in many enterprises [27]; [34]. In addition, decision-making in the organizations was strictly top-down process in all investigated SMEs and, generally, employees are neither actively involved in health and safety activities nor in the decision-making process. Employees in many SMEs generally are not inhibited in raising any safety concerns.

It is essential that employees' health and safety behavior as organizational values are adopted and shared among all employees throughout the organization and not only formally existing. Reviews of organizational value surveys have identified some common constructs related to such values [36] as: described, propagated (formal) and shared or real values. Employees' attitudes and safety behavior are based on adopted and recognized values. Therefore it is essential that these values can be introduced through management principles, good practices in occupational health and safety, as well as through employers' and employees' commitment to safety on a daily basis [7].

- Senior managers' concern and commitment to safety, as it is evident at all levels in the organization. The necessary allocation of resources, including time, equipment, personnel and finance, is being made.

According to results from the qualitative survey, there is a lack of resources (human and financial) allocated to the field of $\mathrm{OH} \& \mathrm{~S}$ in Estonian SMEs. Employees perceive that 
resources for employees (training, occupational health service, health promotion programs) are a low priority. One possible reason for that could be the economic situation at the time of the study when all organizations tried to reduce costs, including those related to the occupational health and safety. Virovere with colleagues [37] stated that the investigated management values have changed in 2009 (versus 2007), but the need for knowledge management and learning as a value in the organization is not pointed out.

According to the results from the interviews with senior managers, there is a lack of management awareness and commitment to safety. There are still a few incentives and little motivation, especially from relevant Estonian legislation for employers to deal with OH\&S issues in Estonia [7]; [27]. The effectiveness of the present $\mathrm{OH} \& \mathrm{~S}$ system in Estonia is undermined by the insufficient coverage of occupational health services, lack of political will to meet EU occupational health and safety requirements, lack of relevant statistical data and research activities, too weak penalties and the continuing absence of an insurance act for occupational accidents and diseases [25]; [27]; [34].

Personnel perceive that management places a high emphasis on issues related to production and quality of the product and less attention has been devoted to environment, safety and health issues. It means that there is a need to improve visibility and involvement of management in safety-related activities. An integrated and cohesive organizational safety leadership process does not yet exist in Estonian SMEs.

- Roles and responsibilities are clearly defined and understood.

Senior managers and employees have the clearest perception of their roles and responsibilities. Employees and employers share common perceptions of responsibility for managing workplace risks. Most of the employees and all employers are more likely to assume that the employer has responsibility for controlling workplace risks. At the same time, employers have pointed out that they expect more responsibility for safety from their employees (that responsibility for safety should be shared). During the focus group interviews, employees have stated that they do not usually discuss health and safety issues with colleagues and do not show actively co-workers' support for safety.

The current study that is in a line with [18]; [30] shows that the positive safety climate enhances not only employees' personal responsibility for safety but also contributes to coworkers' peer support for safety.

- Safety is integrated into all activities in an organization.

Results from the study reveal that safety has not been consistently integrated into all activities in the investigated eight SMEs yet. Processes and programs are at various stages of transition, relevant information and existing safety knowledge are generally distributed between different departments which often reduce their effectiveness. In addition, the quality of documentation and processes needs to be controlled and improved in six of the eight SMEs. However, in all of the investigated Estonian enterprises written safety procedures for work operations and safety instructions were established. Most employers considered the working environment in their enterprise to be safe [16]; [27] and all investigated enterprises have their own written safety guidelines and procedures, but their fulfilment is not periodically updated and monitored.

The issues of the conflict, as part of the culture, were sensitive in all the investigated SMEs. Therefore, it was not recognized, and certainly not openly and honestly acknowledged. The subject related to the possible conflicts between employers and employees or co-worker was regarded as negative and irrelevant and, thus, rejected. This attitude is typical of the organization that does not recognize the positive power of conflict in the innovative and learning process. Essential aspects of the positive safety culture are the managers' commitment, the employees' involvement and the effective SMS [6]. The established SMS has to be a fully integrated part of its general management system in the organization that addresses occupational accident prevention; preparedness and response (see Fig. 3). The SMS should include the organizational structure, practices, procedures and resources for implementing the safety policy. In order to codify personal tacit knowledge into explicit and practical knowledge for all employees within an organization, it is essential that the process of safety knowledge management needs to be acknowledged and valued by the management.

Establishing of the Community of Practice (CoP) can be moderated by an organizational climate (supportive and open reporting culture that is blame-free) and organizational structure (less formalized, less centralized and more integrated) as well as managed.

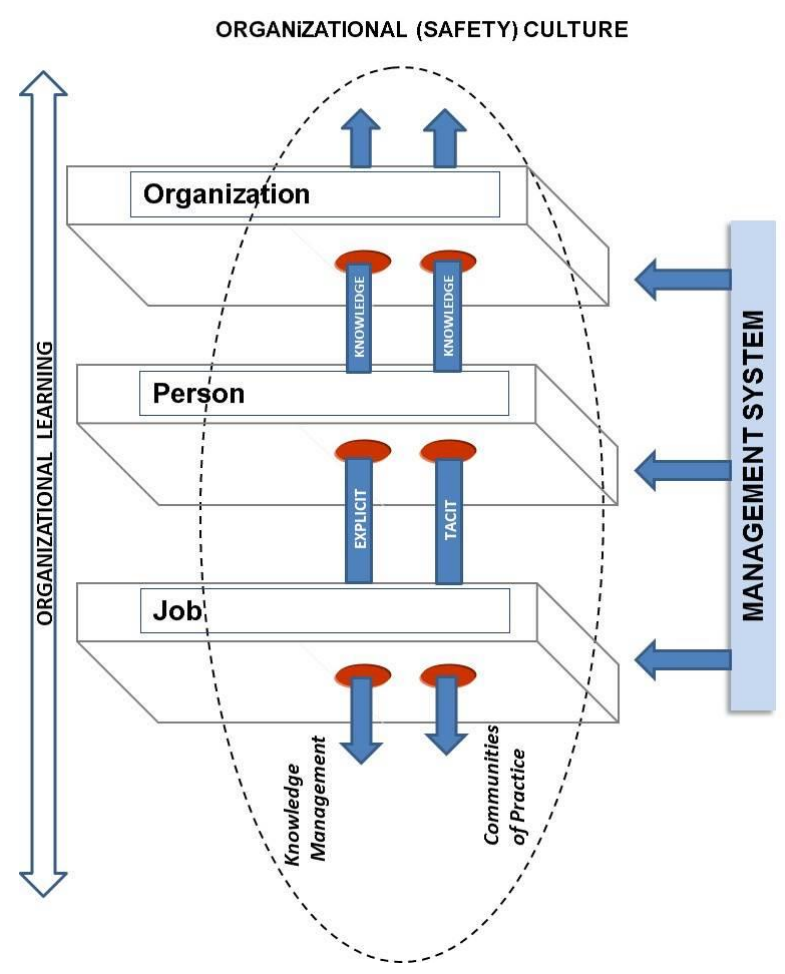

Fig. 3. Tacit and Explicit knowledge management. 
- Safety Culture is learning driven in an organization.

According to the results from safety survey, safety was not learning driven in the investigated SMEs. Efforts to improve future performance by learning from past performance and experience, and from the day-to-day implementation of the organization's programs and processes are not systematic or recognized to be of high value for an organization.

Efforts have recently been undertaken to provide greater management support and attention to the corrective action plan system in all investigated SMEs, especially for training, not always in the field of occupational health and safety. Our study results have revealed that information, both internal and external, is distributed and communicated throughout the organizations by various mechanisms, e.g., e-mails, pre-job briefs, guidelines, written safety instruction, Intranet, and work orders. Although employees demonstrated good awareness of the risks and safety measures in their work environment, some problems still exist in the transmission, comprehension and implementation of the safety information and knowledge, as well as insufficient and formal safety training provided for employees, especially for the new employees [7]. During workplace visits and the interviews, gaps concerning how safety knowledge is transferred were analyzed. Some safety knowledge transfer barriers found in all investigated enterprises were emphasized, such as lack of time and willingness to share information, language issues and expertise [7]; [27]; [34].

Overall, employees were conscious of the importance of working safely; they did not feel that avoiding responsibility out of fear of being punished was a behavior that was valued within an organization. Nevertheless some skepticism still remains with respect to having a truly blame-free environment. According to the results from focus group discussions with employees, there is also a need to establish an open reporting culture that is blame-free.

\section{Gaps Addressed in the Current Model}

There is no survey previously conducted incorporating conflict management as a learning instrument and its possible effect on safety culture and knowledge exchange. Thus, this study fills a key gap in the literature by including this factor. The current study also investigates relationships between employers and employees as well as co-workers, co-workers' peer support for safety and personal responsibility, which is sparsely reviewed in the literature [3], [6], [20], [30], [38].

\section{Limitations}

The setting for this study, in particular, made it difficult to identify safety activities and behaviors that would apply to all employees and employers throughout the investigated organizations in the manufacturing sector. In addition, eight case studies (observations, audits) and a limited number of interviews may represent a small sample. Thus, further research with a larger number of people, including safety managers, must be conducted. The results from the current quantitative and qualitative research cannot be generalized to other small and medium-sized enterprises and play an illustrative role without further research.

Despite these limitations, this study has revealed findings that have both theoretical and practical significance. The implications that these findings have for both safety culture and organizational science research are of particular importance [24]. From a more practical standpoint, it is likely that senior managers can benefit from a balanced approach to safety that includes traditional safety management activities (i.e., management of physical or tangible resources/ assets, such as safer technology, regular audits, hazard identification, proper risk assessment; use of less hazardous chemicals and the elaboration of safe procedures, safety policies and guidelines etc.), but special attention should be devoted to intangible resources/ assets which comprise, what we have called here, the CoP (i.e., employees' capabilities, competence, skills, organizational and safety culture, the company's image, organization's resources, way of action and relationships).

\section{Future Directions}

Future research should focus on the understanding of how organizational values are used in an organization and which factors affect their implementation in an organization. More research should be conducted in order to test the proposed model of safety culture and to further validate the survey. Another kind of study approach would be more suitable for probing deeper into safety culture issues at the organizational level, focusing on safety performance and the actual behavior, safety promotion, safety policy and procedures, safety awareness, creation and transfer of safety knowledge. In addition, it would be useful to study how an organization can support collective learning in the field of occupational health and safety as well as identifying the relevant organizational indicators of safety culture, measuring safety culture and organizational values, how these are interrelated and change over time especially in small and medium-sized enterprises. In addition, it would be valuable to obtain information on the safety managers, occupational health specialists, to evaluate the effect of some safe working condition.

\section{CONCLUSIONS}

The present study has examined the subjective architecture of safety culture in the Estonian manufacturing sector in terms of the relationship between organizational, psychological and behavioral aspects of safety culture. A conceptually innovative Reciprocal Model of Safety Culture with Knowledge Dimension was tested with a sample of 463 employers, which could allow an in-depth study of the impact of Knowledge Management on the development of safety culture processes as well as describing the relationship between a safety climate and the overall safety culture through the notion of Community of Practice.

An overview of the safety culture in SMEs was evaluated through multiple data collection. The authors present an empirical examination based on a questionnaire survey with a 
sample of 463 employers and 1757 employees [24] of the relationship between a safety climate and the overall safety culture with a new dimension - knowledge management. Supportive measures for capturing and analyzing the psychological, behavioral and organizational aspects of safety culture included observations, semi-structured in-depth interviews with senior managers, focus group discussions with employees, document analysis and audits. Eight case studies were undertaken to study how in each case the SMS was integrated into the strategic management system, working environment, formal and real safety, the design of a safety knowledge management system and model of safety culture with knowledge management dimensions, safety information needs as well as information sources.

The results illustrate the importance of a positive safety climate in different aspects of safety culture with a special focus on managing safety knowledge within the organization. Factor analysis was conducted to reduce the identified critical safety climate factors to sixteen for the employees [24] and ten for the employers. It was concluded that the integrated approaches of safety climate assessment in the current study could provide reliable prediction of the level of overall safety culture and real state of safety in manufacturing SMEs. This approach has the potential to improve the understanding of different features in SMS in order to manage safety, knowledge and conflicts.

From a theoretical perspective, this study is one of the first to evaluate safety climate dimensions with a special focus on knowledge management systems as an umbrella for capturing a range of organizational concerns in order to enhance learning and performance in an organization. This study concerns organizational safety culture and the structure or architecture of employees' and employers' attitudes to safety as part of that culture, as well as the ability to learn, which also should mean changes in workers' behavior through establishing communities of practice and conflict management in order to enhance safety culture.

Based on the previous research and the results of the study, it can be concluded that the need for the knowledge-based change in the field of occupational health and safety in Estonia is urgent, which could be also one of the effective and most powerful strategies for organizational development. There is also a need for effective knowledge management training - for a support system in order to provide an organization with strategic advantages and help to develop learning environment which can help create and maintain skills in safety and therefore create the positive safety culture. Based on the surveys, authors emphasize that two main factors in the process of managing of safety knowledge and organizational learning essential for strengthening and enhancement of SMS are: development of communities of practice (gives a possibility for learning and transmitting practical safety knowledge and, thus, for collective learning) and supportive and harmonized safety culture where knowledge-sharing is valued by everyone in an organization.

The authors believe that the presented Reciprocal Model of Safety Culture with Knowledge Management System
Dimensions can assist in the on-going analyses and implementation of a positive safety culture.

\section{Acknowledgements}

The authors gratefully acknowledge the valuable comments and suggestions made by Charles Woolfson and assistance provided by Elviira Povel during the elaboration of the article.

\section{REFERENCES}

[1] T. Maudgalaya, A. Genaidy, R. Shell. "Productivity-Quality-CostsSafety: A sustained approach to competitive advantage - a systematic review of the national safety council's case studies in safety and productivity". Human Factors and Ergonomics in manufacturing; 18 (2):152-179, 2008 http://dx.doi.org/10.1002/hfm.20106

[2] L.Y. Yun. "Economic costs of work-related injuries and ill health". Asian-Pacific Newsletter on Occupation Health and Safety, Economics in occupational health and safety, 19(2): 38-39, 2012.

[3] S.B. Frazier, T.D. Ludwig, B. Whitaker, D.S. Roberts. "A hierarchical facto analysis of a safety culture survey". Journal of Safety Research, 45: $15-28,2013$

http://dx.doi.org/10.1016/j.jsr.2012.10.015

[4] E. Hassan, C. Austin, C. Celia, E. Disley, P. Hunt, S. Marjanovic, A. Shehabl, L. Villalba-Van-Dijk, C. Van Stolk. "Health and Wellbeing at Work in the United Kingdom, RAND Technical Report", TR-758DH, RAND Eirope. 2009.

[5] C.Van.Stolk, L. Staetsky, E.Hassan, S.W.Kim. "Management if occupational health and safety. An analysis of the findings of the European Survey of Enterprises on New and Emerging Risk". European Risk Observatory, Report. ISSN 1831-9343, 2012

[6] B. Fernández-Muñiz, J.M. Montes-Peón, C.J. Vázquez-Ordás, "Safety culture: Analysis of the causal relationships between its key dimensions". Journal of Safety research 28, 627-641, 2007. http://dx.doi.org/10.1016/j.jsr.2007.09.001

[7] M. Järvis, A. Virovere, P. Tint. (Submitted for publication). "Formal Safety Versus Real Safety: Quantitative and Qualitative Approaches to Safety Culture - Evidence from Estonia”. Proceedings of the Latvian Academy of Sciences. 2013

[8] C.S. Fugas; S.A. Silva, J.L.Melia. "Another look at safety climate and safety behaviour: Deepening the cognitive and social mediator mechanisms". Accident Analysis and Prevention, 45:468-477, 2012. http://dx.doi.org/10.1016/j.aap.2011.08.013

[9] R.M. Choudhry, D. Fang, S. Mohamed. "The nature of safety culture: A survey of the state-of-the-art". Safety science, 45:993-1012,2007 http://dx.doi.org/10.1016/j.ssci.2006.09.003

[10] M.D. Cooper. "Towards a model of Safety Culture". An abridged version published in Safety Science (2000): Vol 36:111-136. Retrieved from the world wide web, 14.03.2009, http://behavioural.safety.com/arti cles/Towards_A_Model_Of_SAfety_Culture/

[11] F.W. Guldenmund "The nature of Safety culture: A review of theory and research". Safety Science, 34: 215-257. 2000 http://dx.doi.org/10.1016/S0925-7535(00)00014-X

[12] T. Lee, K. Harrison. "Assessing safety culture in nuclear culture power stations". Safety science, 30: 61-97, 2000 http://dx.doi.org/10.1016/S0925-7535(00)00007-2

[13] E.H. Schein. Organizational culture and Leadership, Jossey Bass, San Francisco. 1992

[14] S.Clarke, "Perceptions of organizational safety: implications for the development of safety culture", Journal of organizational Behaviour, 20: 185-198, 1999. http://dx.doi.org/10.1002/(SICI)1099-1379(199903)20:2<185::AIDJOB892>3.0.CO;2-C

[15] M.E.Brown; L.K., Trevino, Ethical Leadership: A review and Future Directions, in A.Crane \& D.Matten (eds) "New Directions in Business Ethics", SAGE Publiation Ltd, Londan: 25-65, 2012

[16] M., Järvis; P.Tint, "The formation of a good safety culture at the enterprise". Journal of Business Economics And Management, 10(2), pp. 169-180, 2009. http://dx.doi.org/10.3846/1611-1699.2009.10.169-180

[17] H.W. Heinrich, D. Peterson, N. Roos. "Industrial Accident Prevention". McGraw-Hill, New York. 1980 
[18] E.A.-L.Teo, Y. Feng. "The Role of Safety Climate in Predicting Safety Culture on Construction Sites". Architectural science Review, 52: 5-16. 2009

[19] M. Valler, A.Virovere. "Structural Capital as the Success Factor. Using Intellectual Capital to Increase the Competitiveness". LOP LAMBERT Academic Publishing. ISBN: 978-3-8383-6204-5, pp 69. 2010

[20] R. Flin, K. Mearns, P. O'Connor, R. Bryden. "Measuring safety climate: identifying the common features". Safety Science 34, 177-192. 2000 http://dx.doi.org/10.1016/S0925-7535(00)00012-6

[21] C.-C.Yang, Y-S. Wang, S-T.Chang, S.-E.Guo, M.-F. Huang,."A Study on the Leadership Behaviour, Safety Culture, and Safety Performance of the Healthcare Industry", Work Academy of Science, Engineering and Technology, 53: 1148-1155, 2009

[22] M. D. Cooper, R. A. Phillips. "Exploratory analysis of the safety climate and safety behaviour relationship". Journal of Safety Research, 35(5): 497-512. 2004 http://dx.doi.org/10.1016/j.jsr.2004.08.004

[23] Ernst \& Young. "The analysis of the cost of implementing the main topics of Occupational Health and Safety regulations". Report (in Estonian) pp 35.2010

[24] M. Järvis, A. Virovere, P. Tint. (Submitted for publication). "Knowledge Management - a neglected dimension in discourse on safety management and safety culture - evidence from Estonia". Scientific Journal of Riga Technical University, Safety of Technogenic Environment. 2013

[25] M. Järvis, P. Tint. "Innovations at workplace: An Evidence-Based Model for Safety Management". Journal Business: Theory and Practice, 10 (2): $150-158.2009$

[26] The Health and Safety Executive. "A review of safety culture and safety climate literature for the development of the safety culture inspection toolkit". Human Engineering Shore House, Bristol. Research report 376. 2005

[27] M. Järvis, P. Tint. "The effects of human resource management practice on development of safety culture". University of Management and Economics, Vilnius Conference proceedings: Insights into the sustainable growth of business. MMRC conference, 19-21 Nov, 2009, Vilnius, CD-ROM: 15 pp., 2009

[28] K.R.Thompson, F. Luthans "Organizational culture: A behavioural perspective". In B.Schneider (ed) 1990. Organizational Culture and Climate. Jossey-Bass, San F.Calif. : 319-344, 1990

[29] S. Silva, M.L. Lima, C. Baptista. "OSCI: an organisational and safety climate inventory". Safety Science, 42: 205-220, 2004 http://dx.doi.org/10.1016/S0925-7535(03)00043-2

[30] J. Harvey, G. Erdos, H. Bolam, M.A.A. Cox, J.N.P. Kennedy, D. Gregory. "An analysis of safety culture attitudes in a highly regulated environment". Work and Stress, 16: 18-36, 2002 http://dx.doi.org/10.1080/02678370110113226

[31] J.Hair, R. Anderson, R. Tatham, W. Black. "Multivariate data analysis with readings" (4th edition). Englewood Cliffs, NJ: Prentice Hall International. 1995
[32] D. Zohar. "The effects of leadership dimensions, safety climate and assigned priorities on minor injuries in work groups", Journal or Organizational Behaviour, 23 (1): 75-92. 2002 http://dx.doi.org/10.1002/job.130

[33] C.S. Lu, K.C. Shang. "An empirical investigation of safety climate in container terminal operators". Journal of Safety Research, 36: 297-308, 2005 http://dx.doi.org/10.1016/j.jsr.2005.05.002

[34] M.Järvis, K.Reinhold, P. Tint. "The innovative tools for prevention of accidents in a post-socialist country". Radim Bris, Carlos Guedes Soares, Sebastián Martorell, ESREL. Reliability, Risk and Safety. Theory and Applications. London: Taylor \& Francis: 25-30., 2010

[35] F.W. Guldenmund. "The use of questionnaires in safety culture research - an evaluation". Safety Science, 45:723-743, 2007 http://dx.doi.org/10.1016/j.ssci.2007.04.006

[36] A. Virovere, E.Titov, K. Kuimet, M.Meel. "Propagated and Real Values in Estonian Organisations According to Conflict Analysis". International Business - Baltic Business Development, Prause, G., Venesaar, U., Kersten, W (eds.). Peter Lang GmbH: 107-124, 2013.

[37] A. Virovere, E. Titov, M. Meel. "Change of Management Values in Estonian Business Life 2007-2009”, Chinese Business Review, 10 (11): 1028-1042, 2011

[38] E.S. Geller. "Working Safe: How to help People Actively Care for Health and Safety" Boca Raton, FL: Lewis Publisher, 2001.

Marina Järvis (the corresponding author), MSc (Bergen University, Norway), at present she is a doctoral student at the faculty of Economics and Business Administration, Tallinn University of Technology. Currently she is a Lecturer at the Department of Work Environment and Safety, Tallinn University of Technology. She has written 30 scientific papers; she has many times represented Estonia at the international OH\&S conferences and participated in relevant projects. Research interests focus on safety culture, knowledge management in OH\&S; safety management system; occupational wellbeing. E-mail: Marina.Jarvis@ttu.ee

Anu Virovere, MSc (Tallinn University), at present she is a doctoral student at the faculty of Economics and Business Administration, Tallinn University of Technology. Currently she is a Lecturer at the Faculty of Business Administration, Tallinn University of Technology, Estonian Entrepreneurship University of Applied Sciences, Estonian Business School. She has written 22 scientific papers; she participated in the international conferences. Research interests focus on conflict management, value based management, ethics. E-mail: Anu.virovere@eek.ee

Piia Tint, doctoral degree (Technical Sciences, 1977) from Leningrad Technological Institute of Lensoveta. Professor; the Head of the Department of Work Environment and Safety, Tallinn University of Technology; more than 150 scientific papers, and 10 books. Main research interests: risk assessment tools, chemical risks, occupational hazards. E-mail: Piia.Tint@ttu.ee 